\title{
PENERAPAN K3 SEBAGAI UPAYA PENCEGAHAN PENYAKIT AKIBAT KERJA PADA PERAWAT
}

\section{PRIMA SITEPU}

\section{Primasitepu01@gmail.com}

\section{Latar Belakang}

Pelaksanaan Kesehatan dan Keselamatan Kerja (K3) adalah salah satu bentuk upaya untuk menciptakan tempat kerja yang aman, sehat, bebas dari pencemaran lingkungan, sehingga dapat mengurangi dan atau bebas dari kecelakaan kerja dan penyakit akibat kerja yang pada akhirnya dapat meningkatkan efisiensi dan produktivitas kerja. Tujuan: untuk mencegah kecelakaan di rumah sakit. Pelaksanaan Kesehatan dan Keselamatan Kerja (K3) adalah salah satu bentuk upaya untuk menciptakan tempat kerja yang aman, sehat, bebas dari pencemaran lingkungan, sehingga dapat mengurangi dan atau bebas dari kecelakaan kerja dan penyakit akibat kerja yang pada akhirnya dapat meningkatkan efisiensi dan produktivitas kerja.

Kecelakaan kerja tidak saja menimbulkan korban jiwa maupun kerugian materi bagi pekerja dan pengusaha, tetapi juga dapat mengganggu proses produksi secara menyeluruh, merusak lingkungan yang pada akhirnya akan berdampak pada masyarakat luas. Penyakit Akibat Kerja (PAK) dan Kecelakaan Kerja (KK) di kalangan petugas kesehatan dan non kesehatan kesehatan di Indonesia belum terekam dengan baik. Jika kita pelajari angka kecelakaan dan penyakit akibat kerja di beberapa negara maju (dari beberapa pengamatan) menunjukan kecenderungan peningkatan prevalensi. Sebagai faktor penyebab, sering terjadi karena kurangnya kesadaran pekerja dan kualitas serta keterampilan pekerja yang kurang memadai.

Banyak pekerja yang meremehkan risiko kerja, sehingga tidak menggunakan alat-alat pengaman walaupun sudah tersedia. Dalam Undang-Undang Nomor 23 Tahun 2003 tentang Kesehatan, Pasal 23 dinyatakan bahwa upaya Kesehatan dan Keselamatan Kerja (K3) harus diselenggarakan di semua tempat kerja, khususnya tempat kerja yang mempunyai risiko bahaya kesehatan, mudah terjangkit penyakit atau mempunyai karyawan paling sedikit 10 orang. Jika memperhatikan isi dari pasal di atas maka jelaslah bahwa Rumah Sakit (RS) termasuk ke dalam kriteria tempat 
kerja dengan berbagai ancaman bahaya yang dapat menimbulkan dampak kesehatan, tidak hanya terhadap para pelaku langsung yang bekerja di RS, tapi juga terhadap pasien maupun pengunjung RS. Sehingga sudah seharusnya pihak pengelola RS menerapkan upaya-upaya K3 di RS.

\section{METODE}

Metode penelitian yang digunakan adalah literature review dengan cara menganalisis artikel, jurnal maupun textbook yang berkaitan dengan pembelajaran mahasiswa keperawatan belajar berpikir krits untuk membuat keputusan dalam tindakan keperawatan.

Artikel yang digunakan 14 referensi yang diterbitkan sepuluh tahun terakhir yang menggunakan google scholar,google book dan science direct., Dalam mencari artikel, kata kunci yang digunakan ialah Meningkatnya status Akreditas rumah sakit mempengaruhi keselamatan pasien.

\section{HASIL}

Berdasarkan hasil pencarian analisis, eksplorasi dari berbagai sumber didapatkan bahwa tingkat pengetahuan K3 perawat sangat penting dalam menjaga keselamatan pasien dan diri perawat itu sendiri sesuai dengan penelitian terdahulu bahwa didapatkannya hubungan bermakna antara tingkat pengetahuan perawat dengan tindakan keselamatan terhadap pasien.

Menurut Keputusan Menteri Kesehatan RI No.432/MENKES/SK/IV/2007, Kesehatan Kerja bertujuan untuk peningkatan dan pemeliharaan derajat kesehatan fisik, mental dan sosial yang setinggi tingginya bagi pekerja di semua jenis pekerjaan, pencegahan terhadap gangguan kesehatan pekerja yang disebabkan oleh kondisi pekerjaan.

perlindungan bagi pekerja dalam pekerjaannya dari risiko akibat faktor yang merugikan kesehatan; dan penempatan serta pemeliharaan pekerja dalam suatu lingkungan kerja yang disesuaikan dengan kondisi fisiologi dan psikologisnya. Secara ringkas merupakan penyesuaian pekerjaan kepada manusia dan setiap manusia kepada pekerjaan atau jabatannya. Upaya K3 di RS menyangkut tenaga kerja, caralmetode kerja, alat kerja, proses kerja dan lingkungan kerja. Upaya ini meliputi peningkatan, pencegahan, pengobatan dan pemulihan. Kinerja setiap petugas kesehatan dan nonkesehatan merupakan resultante dari tiga komponen K3 yaitu kapasitas kerja, beban kerja dan lingkungan kerja. Komitmen dan Kebijakan Komitmen diwujudkan dalam bentuk kebijakan (policy) tertulis, jelas dan mudah dimengerti serta diketahui oleh seluruh 
karyawan RS. Manajemen RS mengidentifikasi dan menyediakan semua sumber daya esensial seperti pendanaan, tenaga K3 dan sarana untuk terlaksananya program K3 di RS

\section{PEMBAHASAN}

K3RS (Keselamatan dan Kesehatan Kerja Rumah Sakit) adalah segala kegiatan untuk menjamin dan melindungi keselamatan dan kesehatan bagi sumber daya manusia rumah sakit, pasien, pendamping pasien, pengunjung, maupun lingkungan rumah sakit melalui upaya pencegahan kecelakan kerja dan penyakit akibat kerja di rumah sakit. Pengertian tersebut merupakan pengertian yang ada pada Peraturan Menteri Kesehatan Nomor 66 Tahun 2016 tentang Keselamatan dan Kesehatan Kerja Rumah Sakit. K3RS sangat perlu untuk dilaksanakan karena banyaknya risiko yang dialami oleh tenaga medis di fasilitas rumah sakit. Selain itu, K3RS juga disyaratkan oleh regulasi-regulasi di Republik Indonesia.

Tujuan K3RS (Keselamatan dan kesehatan kerja rumah sakit)

- Berdasarkan Permenkes nomor 66 tahun 2016 tentang Keselamatan dan Kesehatan Kerja Rumah Sakit, beberapa tujuan dalam pelaksanaan K3RS dapat dirangkum:

- Keselamatan dan keamanan di Rumah Sakit bertujuan untuk mencegah terjadinya kecelakaan.

- Manajemen risiko K3RS bertujuan untuk meminimalkan risiko keselamatan dan kesehatan di Rumah Sakit sehingga tidak menimbulkan efek buruk terhadap keselamatan dan kesehatan SDM Rumah Sakit, pasien, pendamping pasien, dan pengunjung.

- Pengaturan K3RS bertujuan untuk terselenggaranya keselamatan dan Kesehatan Kerja di Rumah Sakit secara optimal, efektif, efisien dan berkesinambungan.

- Pengelolaan Bahan Berbahaya dan Beracun (B3) dari aspek keselamatan dan Kesehatan Kerja Rumah Sakit bertujuan untuk melindungi sumber daya manusia Rumah Sakit, pasien, pendamping pasien, pengunjung, maupun lingkungan Rumah Sakit dari pajanan dan limbah Bahan Berbahaya dan Beracun (B3).

- Pencegahan dan pengendalian kebakaran bertujuan untuk memastikan SDM Rumah Sakit, pasien, pendamping pasien, pengunjung, dan aset Rumah Sakit aman dari bahaya api, asap, dan bahaya lain. 
- Pengelolaan prasarana Rumah Sakit dari aspek keselamatan dan Kesehatan Kerja bertujuan untuk menciptakan lingkungan kerja yang aman dengan memastikan kehandalan sistem utilitas dan meminimalisasi risiko yang mungkin terjadi.

- Pengelolaan peralatan medis dari aspek keselamatan dan Kesehatan Kerja Rumah Sakit bertujuan untuk melindungi SDM Rumah Sakit, pasien, pendamping pasien, pengunjung, maupun lingkungan Rumah Sakit dari potensi bahaya peralatan medis baik saat digunakan maupun saat tidak digunakan.

- Kesiapsiagaan menghadapi kondisi darurat atau bencana bertujuan untuk meminimalkan dampak terjadinya kejadian akibat kondisi darurat dan bencana yang dapat menimbulkan kerugian fisik, material, dan jiwa, mengganggu operasional, serta menyebabkan kerusakan lingkungan, atau mengancam finansial dan citra Rumah Sakit.

- Unit Pelayanan Kesehatan Kerja Rumah Sakit bertujuan untuk menurunkan kejadian dan prevalensi penyakit pada SDM Rumah Sakit dari penyakit menular, penyakit tidak menular, penyakit akibat kerja, dan kecelakaan akibat kerja.

Sistem Keselamatan dan Kesehatan Kerja Rumah Sakit

Sistem Keselamatan dan Kesehatan Kerja Rumah Sakit (SM K3RS) meliputi 5 hal berdasarkan Peraturan Menteri Kesehatan Nomor 66 Tahun 2016:

1. penetapan kebijakan K3RS;

2. perencanaan K3RS;

3. pelaksanaan rencana $\mathrm{K} 3 \mathrm{RS}$;

4. pemantauan dan evaluasi kinerja K3RS; dan

5. peninjauan dan peningkatan kinerja K3RS. 


\section{Kebijakan K3RS}

Kebijakan K3RS ditetapkan secara tertulis dengan Keputusan Kepala atau Direktur Rumah Sakit dan disosialisasikan ke seluruh SDM Rumah Sakit. Kebijakan K3RS meliputi:

Penetapan kebijakan dan tujuan dari program K3RS:

Kebijakan dan tujuan K3RS ditetapkan oleh pimpinan tertinggi Rumah Sakit dan dituangkan secara resmi dan tertulis. Kebijakan tersebut harus jelas dan mudah dimengerti serta diketahui oleh seluruh SDM Rumah Sakit baik manajemen, karyawan, kontraktor, pemasok dan pasien, pengunjung, pengantar pasien, tamu serta pihak lain yang terkait dengan tata cara yang tepat. Selain itu semuanya bertanggung jawab mendukung dan menerapkan kebijakan pelaksanaan K3RS tersebut, serta prosedur-prosedur yang berlaku di Rumah Sakit selama berada di lingkungan Rumah Sakit. Kebijakan K3RS harus disosialisasikan dengan berbagai upaya pada saat rapat pimpinan, rapat koordinasi, rapat lainnya, spanduk, banner, poster, audiovisual, dan lain-lain.

Penetapan organisasi K3RS dantujuan dari program K3RS

Dalam pelaksanaan K3 Rumah Sakit memerlukan organisasi yang dapat menyelenggarakan program K3RS secara menyeluruh dan berada di bawah pimpinan Rumah Sakit yang dapat menentukan kebijakan Rumah Sakit. Semakin tinggi kelas Rumah Sakit umumnya memiliki tingkat risiko keselamatan dan Kesehatan Kerja yang lebih besar karena semakin banyak pelayanan, sarana, prasarana dan teknologi serta semakin banyak keterlibatan manusia di dalamnya (sumber daya manusia Rumah Sakit, pasien, pengunjung, pengantar, kontraktor, dan lain sebagainya).

Untuk terselenggaranya K3RS secara optimal, efektif, efesien dan berkesinambungan, Rumah Sakit membentuk atau menunjuk satu unit kerja fungsional yang mempunyai tanggung jawab menyelenggarakan K3RS. Unit kerja fungsional dapat berbentuk komite tersendiri atau terintegrasi dengan komite lainnya, dan/atau instalasi K3RS. 
Kebutuhan untuk membentuk unit kerja fungsional tersebut disesuaikan dengan besarnya tingkat risiko keselamatan dan Kesehatan Kerja, sehingga pada Rumah Sakit dapat memiliki komite atau instalasi K3RS, atau memiliki keduanya.

Penetapan dukungan pendanaan, sarana, dan prasarana.

Dalam pelaksanaan K3RS diperlukan alokasi anggaran yang memadai dan sarana prasarana lainnya. Hal ini merupakan bagian dari komitmen pimpinan Rumah Sakit.

\section{Perencanaan K3RS}

Rumah Sakit harus membuat perencanaan K3RS yang efektif agar tercapai keberhasilan penyelenggaraan K3RS dengan sasaran yang jelas dan dapat diukur. Perencanaan K3RS dilakukan untuk menghasilkan perencanaan strategi K3RS, yang diselaraskan dengan lingkup manajemen Rumah Sakit.

Perencanaan K3RS tersebut disusun dan ditetapkan oleh pimpinan Rumah Sakit dengan mengacu pada kebijakan pelaksanaan K3RS yang telah ditetapkan dan selanjutnya diterapkan dalam rangka mengendalikan potensi bahaya dan risiko K3RS yang telah teridentifikasi dan berhubungan dengan operasional Rumah Sakit. Dalam rangka perencanaan K3RS perlu mempertimbangkan peraturan perundangundangan, kondisi yang ada serta hasil identifikasi potensi bahaya keselamatan dan Kesehatan Kerja.

\section{Pelaksanaan Rencana K3RS}

Program K3RS dilaksanakan berdasarkan rencana yang telah ditetapkan dan merupakan bagian pengendalian risiko keselamatan dan Kesehatan Kerja. Adapun pelaksanaan K3RS meliputi:

1. Manajemen risiko K3RS;

2. Keselamatan dan keamanan di Rumah Sakit;

3. Pelayanan Kesehatan Kerja;

4. Pengelolaan Bahan Berbahaya dan Beracun (B3) dari Aspek keselamatan dan Kesehatan Kerja;

5. Pencegahan dan pengendalian kebakaran; 
6. Pengelolaan prasarana Rumah Sakit dari Aspek keselamatan dan Kesehatan Kerja;

7. Pengelolaan peralatan medis dari Aspek keselamatan dan Kesehatan Kerja; dan

8. Kesiapsiagaan menghadapi kondisi darurat atau bencana. Pelaksanaan K3RS tersebut harus sesuai dengan standar K3RS.

\section{Susunan / Organisasi K3-RS}

Susunan Unit K3-RS terdiri dari :

- Bidang I : Bidang pengamanan peralatan medik, pengamanan radiasi dan limbah radioaktif

- Bidang II : Bidang pengamanan peralatan nonmedik, pengamanan dan keselamatan bangunan

- Bidang III : Bidang pengembangan sanitasi sarana kesehatan

- Bidang IV : Bidang pelayanan kesehatan kerja dan pencegahan penyakit akibat kerja

- Bidang V : Bidang pencegahan dan penanggulangan bencana

Tugas Unit Organisasi K3-RS

- Memberi rekomendasi dan pertimbanagan kepada Direktur RS tentang masalah-masalah yang berkaitan dengan K3_RS, Membuat program K3-RS, Melaksanakan program K3_RS, Melakukan evaluasi program K3-RS

2. Tahap Pelaksanaan

Program K3-RS

1. Pelaksanaan kesehatan kerja bagi karyawanb ( prakerja, berkala, khusus ).(2). Upaya pengamanan pasien, pengunjung dan petugas. (3). Peningkatan kesehatan lingkungan. (4). Sanitasi lingkungan RS. (5). Pengelolaan dan pengolahan limbah padat, cair, gas. (6). Pencegahan dan penanggulangan bencana (Disaster program). (7). Pengelolaan jasa, bahan dan barang berbahaya. (8).Pendidikan dan pelatihan K3. (9). Sertifikasi dan kalibrasi sarana, prasarana, dan peralatan RS. (10). Pengumpulan, pengolahan dan pelaporan K3 Tahap Pemantauan dan Evaluasi

1. Inspeksi dan audit program K3.(2).Perbaikan dan pengendalian K3 yang didasarkan atas hasil temuan dari audit dan inspeksi. (3). Rekomendasi dan tindak lanjut hasil evaluasi program K3 


\section{PENUTUP}

Seorang tenaga kesehatan atau perawat harus mengetahui tiga komponen K3 yaitu kapasitas kerja, beban kerja dan lingkungan kerja. Dan seorang perawat juga harus mengetahui Komitmen dan Kebijakan Komitmen diwujudkan dalam bentuk kebijakan (policy) tertulis, jelas dan mudah dimengerti serta diketahui oleh seluruh karyawan RS, agar tenaga kesehatan khususnya perawat terhindar dari risiko bahaya kerja di rumah sakit.

\section{DAFTAR PUSTAKA}

Arrazy,S., dkk. (2014). Penerapan Sistem manajemen keselamatan kebakaran di rumah sakit dr. sobirin kabupaten musi rawas tahun 2013. Jurnal ilmu kesehatan masyarakat,5, 103-111.

Bawelle, S.C. (2013). Hubungan pengetahuan dan sikap perawat dengan pelaksanaan keselamatan pasien (patient safety) di ruang rawat inap RSUD liun kendage tahune. E-journal Keperawatan. 1(1), 1-7.

Ibrahim,H., Damayanti, D.S., Amansyah, M.,\& Sunandar. (2017). Gambaran penerapan standar manajemen keselamatan dan kesehatan kerja rumah sakit di rumah sakit umum daerah haji Makassar. Al-Sisah: Public Health Science Journal, 9(2), 160-173.

Indrayani, P. (2016). Penerapan safety inspection sebagai upaya pencegahan kecelakaan kerja di PT. Multimas nabati asahan kuala tanjung tahun 2016 (Skripsi, Universitas Sumatera Utara).

Iskandar, E. (2017). Tata Kelola dan Kepatuhan Penerapan Standar Patient Safety Penyakit Stroke di Rumah Sakit Dr. Kanujoso Djatiwibowo Tahun 2015. Jurnal ARSI .3 (3):1-12.

Permenkes nomor 1691/Menkes / V / 2011. Tentang Keselamatan Pasien.

Permenkes nomor 66/ Menkes/ 2016. Tentang Keselamatan dan Kesehatan Kerja. 
Putri,S., Santoso., Rahayu, E. P. (2018). Pelaksanaan keselamatan dan kesehatan kerja terhadap kejadian kecelakaan kerja perawat rumah sakit. Jurnal Endurance, 3(2), 271-277.

Porajow, M.C,.dkk. (2016). Analisis penerapan standar pelayanan kesehatan dan keselamatan kerja rumah sakit (K3RS) di RSUP ratatotok buyat ratatotok kabupaten minahasa tenggara. Jurnal fakultas kesehatan masyarakat universitas sam ratulangi, 1(7), 1-10.

Rahmawati,R..(2017). Gambaran penerapan program keselamatan dan kesehatan kerja rumah sakit (K3RS) pada perawa di RSUD Tugurejo semarang (skripsi, universitas diponegoro).

Simamora, R. H. (2020). Pelatihan Komunikasi Efektif untuk Meningkatkan Efikasi diri Perawat dalam Pelaksanaan Identifikasi Pasien. JURNAL ILMIAH KESEHATAN MASYARAKAT: Media Komunikasi Komunitas Kesehatan Masyarakat, 12(1), 49-54.

Simamora, R. H. (2011). ROLE CONFLICT OF NURSE RELATIONSHIP WITH PERFORMANCE IN THE EMERGENCY UNIT OF HOSPITALS RSD DR. SOEBANDI JEMBER. The Malaysian Journal of Nursing, 3(2), 23-32. 